\title{
DIVISION VII: GALACTIC SYSTEM
}

(SYSTEME GALACTIQUE)

\section{PRESIDENT: K. Freeman}

BOARD: G. Da Costa, J. Binney, L. Blitz, F. Matteucci \& D. Spergel

\section{Commission 33: Structure and Dynamics of the Galactic System} Commission 37: Star Clusters and Associations

The scientific interests of Division VII are concerned with the Galactic system. Its two constituent commissions are Commission 33 (Structure and Dynamics of the Galactic System) and Commission 37 (Star Clusters and Associations). Please refer to the reports of these two commissions for the scientific highlights and lists of major conferences in this area.

Study of the Galactic system involves a wide range of astrophysics and astronomical techniques, and the fields covered by many other commissions are therefore of very significant interest to Division VII. In particular, astronomers with interests in the Galactic system could consider reading also the reports of Commissions 5, 7, 24-30, 34-36, 40, 44 and 45, among others. 